\title{
Gender Inequality in the Division of Household Labour in Tanzania
}

\author{
Sheryl Feinstein \\ Augustus College, Sioux \\ Email:Sheryl.Feinstein@augie.edu \\ Rachel Feinstein \\ Texas $A$ \& $M$, USA \\ and \\ Sophia Sabrow \\ Department of Sociology \\ University of Colonne, Germany
}

\begin{abstract}
This study examined the gender norms and the language used for rationalising gender inequality regarding the division of household labour in Tanzania. Tanzanian university students and secondary students participated in interviews, focus groups, and surveys for this study. Findings suggest that Tanzanian men have very traditional expectations regarding gender roles while Tanzanian women have more progressive expectations. Some gender norms, including the expectation that women should be responsible for the children and should do more work than men overall, were demonstrated. Naturalisation, the attempt to justify an inequality such as sexism by claiming that the disparity is simply natural, was used to explain inequalities; as was minimisation, the attempt to justify an inequality by reducing the significance of the problem. Lastly, cultural sexism attempted to justify gender inequality by explaining the differences between genders as a result of cultural practices rather than sexism.
\end{abstract}

\section{Introduction}

Gender equality, usually considered a basic human right, has not been absolutely achieved in any country (Newman, 2006). A growing interest in this topic has encouraged organisations like the United Nations to research gender inequality internationally and to develop a mechanism for comparing the level of inequality in each country.

Using the 'gender empowerment measure' (GEM) to represent the inequality of opportunities for men and women in each country, the United Nations ranked the United States (US) $12^{\text {th }}$ and Tanzania $15^{\text {th }}$ out of 177 countries (UNDP, 2008). This significant disparity implies that women in the US participate much more in political and economic sectors of society than women living in Tanzania (Newman, 2006). Although 
the GEM noted a significant difference between the US and Tanzania's level of gender inequality, neither country demonstrated perfect equality. Furthermore, this indicator describes the gender inequality in quantitative terms of access to political power and economics; however, the GEM does not explain the degree of sexism involved in the gender norms of each society.

Sexism is an aspect of gender inequality that is perpetuated through gender norms. Healey explains that there are two types of sexism, hostile and benevolent. Hostile sexism includes agreement with negative stereotypes against women and "anti-minority group prejudice" whereas benevolent sexism is often "expressed as an apparently positive attitude of protection and affection" (2006:99). Although these forms of sexism are seemingly contradictory, Healey asserts that both types of sexism "promote stereotypical views of women and serve to justify and rationalise their lower status" (2006:99). When either form of sexism is used, individuals are expressing traditional attitudes towards gender norms. Although sexism can take many forms, and often works on a structural level, making it difficult to recognise at times, it cannot be overlooked in studying gender roles and the division of labour.

Consistently, research focusing on gender norms in various countries around the world demonstrates a difference between male and female responses. Often this is the most significant finding of research on gender norms. In general, males express "more traditional sex-role attitudes than females" (Rao \& Rao 1985:607; Morinaga, Frieze, Ferligoj 1993:317).

There has been little research conducted on gender roles in Tanzania. However, a study by Susan Rogers focusing on village women in Tanzania in 1983, found that women were aware that they work more than men, but they were unable to change the situation. A local Tanzanian organisation conducted a study in 2006 reaffirming the idea that Tanzanian women are working harder than men (LCCB, 2006). One participant in this study explained that although both boys and girls work on the farm together, afterward "the girl would collect water, cook etc. while the boy is resting waiting for food" (2006: 17). The boys are taught how to become men and perform men's duties while "girls are socialised to perform 'mothers duties"' (2006:17). The Local Community Competence Building (LCCB) organisation in Tanzania describes the inequitable division of labour between boys and girls as "contributing to human rights violation and gender inequity" (2006:24). This study depicts some of the gender norms in Tanzania like the expectation that women will work harder and longer hours than men as well as serve the men. Based on this study, it is predicted that Tanzanian students will describe the women's work day as longer and involving more work than men's work day because of women's housework responsibilities.

The situation is further complicated by the control the men have over women's labour. The men are the supervisors and they also control the finances (Rogers, 1983). For these reasons women are further oppressed by their position as a labourer. Conflict 
theory would likely view the oppression of women as related to the alienation they experience. Women have little contact with other women who suffer the same problems, and they do not see the results of their labour (Appelrouth, 2007). Rogers explains that women do not come to a "full realisation of the implications" of their positions as labourers and they agree to these tasks "because of the ideals inculcated in [them] by social norms" (Roger,s 1983:37). Because of the disconnection women have between their labour and the financial rewards, they experience alienation and do not feel like their work has the same amount of meaning as it does for the men (Appelrouth, 2007). This study demonstrates how the gender norms that allow for extreme gender inequality are perpetuated due to the dominating role men play and the alienation, isolation, and lack of power women experience.

\section{Methods}

\section{The Sample}

This study was conducted using qualitative interviews, focus groups and surveys. In both the interviews and the focus groups, interactive conversations were guided and left open-ended (Babbie, 2005). Tanzanian students who were currently attending Tumaini University and secondary school students in Iringa Municipal were interviewed for the study. Fourteen university students and 14 secondary students were interviewed, half from each group were female and half were male. Additionally, two focus groups, one consisting of five female university students at Tumaini and one of five male university students, were conducted. Finally, 210 secondary students were surveyed. The participants' ages ranged from 17 to 30 years-old. This study focused on some of the most educated and thus most likely progressive members of Tanzanian society.

All of the interview participants were collected using a convenient sample. Normally focus groups are not based on random selection and therefore are not representative, because the purpose of these groups is to explore an issue rather than explain it (Babbie, 2005). For this reason, members of the focus groups did not need to be randomly selected for the data to be reliable. Students who were on university or secondary school campuses studying or talking with friends outside were asked to participate in the study either as an interviewee or a member of the focus group. Interviews with university students were conducted in English, while interviews with secondary students were done in Kiswahili.

Students at one government secondary school in Iringa were chosen to participate in the questionnaire. The school site was chosen because it was co-educational and students from the region attended, bringing in a broad perspective. All students in Form 4 took part in the study; 97 were male and 113 were female. The surveys were administered during class time, assuring a $100 \%$ return rate. 


\section{Measurement}

Each interview began by asking the participants how they were raised differently from their siblings of the opposite sex, in order to determine whether the gender inequality that has previously been studied is apparent to local Tanzanians.

In order to receive specific responses it was necessary to probe participants, questioning them on differences in educational success, responsibilities around the house, rules, expectations for marriage, apparent respect from parents, apparent love from parents.

In order to identify the common verbal mechanisms used to rationalise the gender inequality in Tanzania, students were asked to explain why they believe the gender division of labour occurs the way it does in their country. For example, after students described their gender roles they were asked, "Why do you think your parents encouraged your sisters to cook and clean and your brothers to work outside?"

The focus groups were used to enhance the research on verbal mechanisms. However, the questions used in the focus groups were more specific and largely revolved around the gendered division of household labour. The primary purpose of the focus group was to determine the Tumaini University students' expectations in terms of gender roles in marriage.

Instructions for the questionnaire were given in Kiswahili, the students' native tongue. The questionnaire consisted of 30 multiple-choice items and was developed from responses gathered during the interview process. Questions probed into perceptions on the following topics: educational success, work responsibilities, rules, and expectations for marriage. The questionnaire was analyzed using descriptive statistics, responses were tallied and percentages were computed.

Conducting this research as two Americans and a German may have allowed for potential problems with the data. Although all of the university classes were taught in English and all students know the language well, a language barrier was still likely present to various degrees. The vocabulary or the accent may have made it difficult for the participants to correctly understand the questions. Or their responses may have been misunderstood, either in terms of hearing them correctly or interpreting the responses correctly.

Furthermore, there was no access to a recording device so the responses were written down as they were stated. This may have caused problems with accuracy. Only sporadic statements were written down word for word when time allowed.

Since research is not commonly conducted in Tanzania, students may have experienced discomfort throughout the interview process. Particularly, being questioned by white females may have intimidated some participants more. This could have made students feel compelled to use responses that they believed the researchers wanted to hear, therefore altering the validity of the data. 


\section{Results}

\section{Tanzanian Expectations for Division of Household Labour}

Consistent with previous research, responses from Tanzanian men were very different with regards to their expectations for the division of household labour compared to the responses from Tanzanian women. Men had much more traditional expectations for future household gender roles than women, who had very egalitarian aspirations. For example, the men felt that there was no need to change the way labour is currently distributed since women see their jobs as their responsibility. One student explained, "Something that is culture is very difficult to change. It is hard to change. Women naturally themselves found that they are responsible to do those things. So far there is not a need to change because they see it as their responsibility."

However the women were adamant that men should help cook and do half of the housework. A female student summarised the feelings of other participants in the focus group by saying that it is okay for men and women to share the same chores "because we know we are all the same. They have the same brain, two hands. So everything I can do, a man can also do." Since the men do not see a problem even though the women explicitly state that they desire change, this clearly suggests that some form of miscommunication is occurring between the two genders. This miscommunication may be due to the men's desires to deny or ignore how the women are feeling or it could possibly come from an inability of the women to express their selves due to the strong traditional culture in Tanzania.

Tanzanian women seem to desire egalitarian households. There was strong agreement among the women in the focus group that sharing household responsibilities with their husbands was important and was how they were going to carry out their future marriages. One female student explained that the strict gender roles are "part of the culture, but as this time passes the men should help cook". She provided her perspective on sharing household chores, like cooking, saying that "It is happening, but mostly to educated families. In the indigenous family, men can't [cook].” This desire was present in many of the female university students I spoke with, which suggests that currently in Tanzania it may be expected for educated women to want egalitarian divisions of labour. However, one significant distinction between these findings is that most Tanzanian men did not express any feelings of responsibility for household chores. Instead, it can be implied from their responses that in Tanzania the gender norms are very traditional and men are not expected to take on household responsibilities despite the increasing responsibilities of women, nor are they expected to express egalitarian desires.

Despite the desires of Tanzanian women to have egalitarian households, results from the interviews demonstrate that this is not occurring. Instead, the gender norms in 
Tanzania seem to encompass traditional roles for women, causing them to be responsible for all domestic duties. For example, all but one of the respondents from the interviews mentioned that the women were responsible for cooking or performing the 'kitchen duties' in their home. The one student who was raised in a more egalitarian household explained that her situation was very abnormal, and friends and relatives were shocked when her brothers would cook. She explained that her relatives are surprised by this because their culture "prohibit[s] men from going to the kitchen" and says that women are supposed to cook and clean. Other students expressed the same cultural prohibition of men in the kitchen as an explanation for the division of labour. One student in particular explained that he can count on one hand the number of times his father ever entered their kitchen. This division of labour would not necessarily contribute to inequality if it did not signify that women work harder and more often than men. However, this study found that the domestic tasks regarded as a woman's responsibility ensure that women work more than men. Survey respondents corroborated these findings; $0 \%$ of male and female participants believed that men should wash clothes, cook or take care of children, although many women believed that it should be the responsibility of both.

Although more women are receiving higher education and getting jobs outside of the house, they are still expected to take care of the household responsibilities, which further increase the amount of work women do in comparison to men. In fact, both male and female participants acknowledged that women work harder than men. A few male students explained that although their sisters have to be at school at the same time as themselves, the sisters have to wake up earlier to make breakfast and take care of the children. After school, both siblings have homework responsibilities but the women are still expected to do all of the housework, prepare the meals, and take care of younger siblings or their own children. In addition, five of the 28 students specifically stated that women work harder than men. Some students recognised the labour division as oppressive to women and unfair. And many students implied that women work more than men through their descriptions of the gendered responsibilities that they experienced growing up in their homes. These findings suggest that the gender norms in Tanzania include the expectation that women will take care of the household responsibilities even if it means working much harder and longer hours than men.

The gender norms regarding the division of labour seem to revolve around the needs of men. The rules fluctuate to benefit men depending on the particular situation. For example, many students explained that men are prohibited from the kitchen, but they also said that if the women of a household are absent or sick the men are no longer prohibited from cooking. One student explained that, "very rarely boys cooked" like when his mom was sick or the girls were all at school.

In other words, the culture is forgiving enough to allow men to feed themselves when it is essential, but not forgiving enough to give men and women equality. One female 
student further supported this idea when she explained that she and her sisters do the washing and cooking, but her brothers don't do these jobs if a girl is around-"just African culture. If [a] boy is doing something for a girl it's bad". Based on the interview data it was determined that Tanzanian women are expected to serve the men in their culture as part of the gender norms. Although, surprisingly, it was not uncommon for men and women interviewed to mention that the normal rigidity of the gender roles were deviated from when help was necessary.

During the focus group, it was revealed that the gender norms regarding the division of labour are not always as divided as Tanzanian married couples make it seem. A married college student in the group explained that some women who are very 'strong' are able to convince their husbands to help out around the house with the children, cooking, and cleaning. When other students in the focus group tried to qualify his statement by quickly pointing out that this is 'very rare', he continued to explain that it is not really as rare as they think. Living in Tanzanian culture, he said that if he were doing chores to help his wife he would "keep it as a secret because if [his] friends know there will be shame". He believes that men in about $50 \%$ of the married couples help their wives with household duties. This statistic is likely not accurate, but his perception of the situation as an insider in a marriage is interesting. Based on his statement, it is likely true that other Tanzanians are not aware of the real number of husbands who help their wives around the house.

Tanzanian students felt that child raising, cooking and cleaning were more natural for women, while doing outside work is not as natural for them. One student from the focus group explained that it is a good thing that women do not have to go out "looking for cows... It is somehow natural." He immediately continued by stating "for example, getting pregnant is something a man cannot do." Since these three lines were part of his continuous thought process, it appears that this student is using evidence of a biologically determined responsibility (getting pregnant) as support for the notion that women should be working inside rather than outside with animals.

During the male focus group, most of the men made it very clear that they believe they are superior to Tanzanian women. The Tanzanian male students said that many women use the term 'bwana', which means Lord, to refer to their husbands. When the researcher smiled at this, the students assured them it was not a joke, but instead it refers to the 'high class' of man. One male student who was interviewed also explained that his sister and he were respected by their parents equally as children, but as they grow up girls are supposed to respect men. And one female student interviewed said that the reason men don't cook and clean is because "men think they are superior so they refuse".

This suggests that sexism is not heavily stigmatised in Tanzania. Furthermore, responses derived from the focus group give the impression that some Tanzanian students, particularly males, are proud of being sexist and claiming their believed superiority over women. 


\section{Language Used to Rationalise Gender Inequality}

Bonilla-Silva developed frameworks that are commonly used by Americans to rationalise racism. Applying these to the issue of gender demonstrates how individuals use a similar process to rationalise gender inequality. Ferber used Bonilla-Silva's frameworks in examining the gender ideology of United States citizens. She was able to apply all four frameworks, naturalisation, minimization, cultural [sexism], and abstract liberalism to the gender ideology of the US, implying that Americans attempt to avoid sounding sexist despite the reality that gender inequality does indeed exist. By analyzing the data collected from Tanzanian university students, it is possible to determine whether a similar process of rationalisation is occurring in their culture as well. The results from Tanzanian students demonstrated that three out of the four frameworks are commonly used; naturalisation, minimisation, and cultural sexism.

\section{Naturalisation:}

Although Tanzanian women never spoke of their gendered chores as natural in the interviews or focus group, the men in the focus group did use this explanation for the inequality. The actual term 'natural' was used a couple of times throughout the focus group session. The students did not seem to have a specific explanation for the naturalness they assigned to women's responsibilities; they simply explained that they were 'somehow natural'. As previously noted, when questioned for specific explanations, students provided the concept of 'getting pregnant', which 'is something a man cannot do'. The students attempted to make the argument that other inside chores like cooking, cleaning, raising children, are naturally a woman's responsibility simply because one biological process, getting pregnant, is only physically possible for females. Using naturalisation as an explanation for all women's responsibilities, allows Tanzanians to feel justified in assigning more tasks to women.

Naturalisation was also used by participants when discussing the disparity in the amount of respect given to females and males. The male students in the focus group were asked how they would respond if their future wives wanted equal respect from them, or even demanded equal respect of them. A member of the male focus group plainly stated, "if you deserve to be respected I will respect you naturally." Respect should not be demanded, he firmly believed. Most of the other members of the focus group concurred with the notion that respect should not be demanded by women. His argument used naturalisation to deny the gender inequality that has been socially constructed and maintained in Tanzania. By claiming that people are either naturally deserving of respect or not, the student is attempting to excuse the general lack of respect towards women in Tanzania. Instead of the blame for this inequality resting on 
the shoulders of Tanzanian men, it belongs to nature. Furthermore, something that is natural cannot be changed through social action. In other words, the naturalisation of gender inequality allows for the continuation of the problem because it is supposedly beyond human decision.

\section{Cultural Sexism:}

During the interviews students used various explanations for the gendered division of labour in order to avoid explicitly saying that their chores are divided in a sexist way. Almost all students described the gendered division of labour as 'Tanzanian culture' or 'African tradition'. The word 'culture' or 'tradition' was used by nearly every student interviewed in order to explain the current household labour division. When asked to explain further, no one could give a thorough response. A female participant from the focus group explained that the division of household labour is "a form of culture. They [men] won't be respected by the community [if] women are up." Others attempted to explain culture's role by stating that the household labour division is something their ancestors had done, which is probably the reason their parents maintained the same gender roles and passed them on. Many students did not see the passing of these traditions as problematic or worthy of critiquing. In response to the question "Why do you think the culture is this way?" (Regarding the gendered labour division) one student casually said, "Maybe from the past but we don't know why we are doing this." Students explained the unequal division of household labour as being caused by tradition and culture rather than by sexism.

\section{Minimisation:}

Regarding the issue of respect, minimisation was used to rationalise sexist interactions. One female who was interviewed felt that she was given more respect than her brothers by her mother. However, when it came to her father, the brothers received more respect. She believed this was due to the fact that they are older than her. Since the father's role in the family and in society is more powerful and influential than that of her mother's, it is likely that 'earning' the father's respect is more meaningful than earning the mother's. Since this student seems to disregard the power differential between her mother and father, it is easy for her to rationalise the lack of respect she receives from her father as fair. After all, she is receiving more respect from her mother, so it is only fair that her brothers receive more respect for her father. By ignoring the significance of gender, she is able to minimise her own situation rather than acknowledging the sexism that is at work within the family structure.

This student also used another form of minimisation. She described her brothers as receiving more respect from her father due to their age. Some of the other female 
students also explained that their brothers were given more respect than themselves, but they believed this was an issue of age rather than gender as well. By focusing on ageism as the culprit, students are minimising the significance that sexism plays in their culture. This allows the sexism to continue because it goes unnoticed. On the other hand, one male student mentioned that his sisters received more respect than himself because they were older. This suggests that age sincerely plays a role in Tanzanian culture, but whether gender tends to override age or vice versa is not strongly demonstrated in this data.

Abstract Liberalism, the fourth framework of Bonilla-Silva's, is not present in the study on Tanzanian university students. Since abstract liberalism is an idea based on values of individualism and succeeding based on one's own merit, it likely fits with American culture better than Tanzanian. With a more communal style culture, Tanzanians likely disagree with the American "not in my backyard" motto, which describes the attitude that change is okay as long as it does not effect $m y$ life. The fact that Ferber was able to recognise all four frameworks being used in the US whereas this study found that Tanzanians only seem to use three of the frameworks, suggests that there is less stigmatisation of sexism in Tanzanian culture. This finding, is supported by the lack of inhibition Tanzanians felt towards talking about the superiority of men. If sexism is less stigmatised and therefore more socially acceptable in Tanzania than the US, Tanzanians do not need to deny or justify the gender inequality by using these frameworks. Since the frameworks are a way for individuals and societies to overlook and deny the reality of a problem like sexism, they should be more commonly used in countries where sexism is stigmatised although it continues to exist, like the United States.

\section{Discussion}

The difference between Tanzanian men and women's desires for the divisions of household labour helps explain why the transition to a more egalitarian division is not occurring. As the primary holders of economic and political power, men are ultimately the decision-makers regarding social expectations and norms. The dominating role of men was also demonstrated by their lack of attention to the egalitarian desires of women. By ignoring or disallowing the expression of women's opinions, men can continue promoting the same norms, values, and gendered divisions of labour that have historically benefited them.

Similarly, with the transition from women working solely inside the home to receiving more education and working at paid jobs, their responsibilities have now doubled. Rather than logically dividing the household labour equally between men and women, the cultural expectations have remained static, which promotes the continued privilege of men. The fact that neither females nor males denied that women indeed work harder than men suggests it is true that Tanzanian women are working more than their male 
counterparts. Since women are working harder than men, they are probably less capable of sparing energy to analyze their situation as the primary labourers with little payback, or to fight against this inequality. As Baxter pointed out, the overwhelming responsibilities of women decrease their ability to gain economic or political independence, and because of that they do not have the capabilities to effectively advocate against their situation (1997).

Another contribution to the continuation of disadvantageous gender norms, and division of labour in particular, is the perception of the situation compared to the reality. Tanzanian men were quick to assume that men have all of the control in a marriage and provide little assistance to their wives. However, one male student that was already involved in a marriage, along with many female students explained that the reality can be very different. They provided examples of women who made their husbands help with household duties. And these individuals perceived this marriage dynamic to be common, whereas other male students, who had not yet been involved in a marriage, perceived the situation to be strictly aligned with the cultural expectations. Although, neither perception can be generalised to describe the reality of what is actually occurring within Tanzanian marriages and homes, it can be determined from this study that the reality for many families is inconsistent from the perceptions of many individuals.

It is likely that the inconsistency between perceptions of the division of labour and the reality helps reinforce the status quo. Since men are the decision-makers and the privileged members of Tanzanian society, the majority of those men who have preconceived notions that the traditional gender roles are the norm, they will likely ensure that their expectations will be met. On the other hand the perception of many women that the gender roles are changing makes them content with the current situation. It also allows sexism to continue because the women do not see the need to fight against the situation.

Minimisation, naturalisation, and cultural sexism contribute to the problem of sexism by allowing the complexity of inequality to be overlooked. Instead of Tanzanians viewing the gendered division of labour as a social construction that privileges men most people see the division as being derived from natural processes or choices. Additionally, using culture and ageism instead of sexism to explain the gender inequality provides more forgivable explanations. These frameworks prevent people from focusing on the central problems leading to inequality, which often allows individuals to overlook inequality all together. Inevitably, the use of these frameworks perpetuates sexism and the inequality of the division of labour in Tanzania.

For future research on the gender norms and inequality in Tanzania it would be beneficial to collect data from a random sample of Tanzanian university students. This would allow for generalisable data. In addition, a larger sample would also be useful since it would make the data more reliable. 


\section{References}

Appelrouth, S., Edles, LD., 2007. Sociological Theory in the Contemporary Era. Pine Forge Press. CA.

Babbie, E., 2005. The Basics of Social Research. Wadsworth. Canada.

Baxter, J., 1997. Gender Equality and Participation in Housework: A Cross-

National Perspective. Journal of Comparative Family Studies. Autumn.

28.3: 220-247.

Bonilla-Silva, E., 2006. Racism without Racists. Second Edition. Rowman and Littlefield. Oxford.

Ferber, AL., 2007. Color-Blind Racism and Post-Feminism: The Contemporary

Politics of Inequality. PP 551-556. Roxbury Publishing.

Healey, JF., 2006. Race Ethnicity, Gender, and Class. Pine Forge Press. CA.

Local Community Competence Building (LCCB) and HIV/AIDS

Prevention Programme in Tanzania (2006). Human Rights and Gender

Equality. Arusha, Tanzania. Local Community Competence Building (LCCB) and HIV/AIDSPrevention Programme in Tanzania (Dec. 2006). Traditional Customs, Human Rights, Gender, and HIV/AIDS in Tanzania. A Research Report. European Union.

Morinaga, Yasuko, Frieze, Irene Hanson, Ferligoj, Anuska. "Career Plans and

Gender-Role Attitudes of College Students in the United States, Japan, and Slovenia." Sex Roles. 1993.

Newman, M, SASI Group (University of Sheffield) 2006. Gender Empowerment. http://www.worldmapper.org/posters/worldmapper_map181_ver5.pdf Retrieved March 18, 2008.

Rao, VV, Prakasa RVN 1985. Sex-Role Attitudes Across Two Cultures: United Status and India. Sex Roles.

Rogers, SG., 1983. Efforts Toward Women's Development in Tanzania: Gender Rhetoric vs. Gender Realities. Women in Developing Countries: A Policy Focus. 23-41.

United Nations Development Programme (UNDP), 2008. Human Development Reports. http://hdrstats.undp.org/indicators/279.html Retrieved Mar 18, 2008. 